\title{
Catalytic monoalkylation of 1,2-diols
}

\author{
Toshihide Maki, Nobuto Ushijima, Yoshihiro Matsumura and Osamu Onomura* \\ Graduate School of Biomedical Sciences, Nagasaki University, 1-14 Bunkyo-machi, Nagasaki \\ 852-8521, Japan
}

\begin{abstract}
A catalytic monoalkylation of 1,2-diols by using a weak base has been developed. Copper(II) dichloride and boronic acids are effective catalysts for activating 1,2-diols in the presence of potassium carbonate as a base. Various 1,2-diols were selectively monoalkylated with allyl-, benzyl- and alkyl- halides in DMF by choosing a suitable catalyst for each 1,2-diols.
\end{abstract}

Selective monoalkylation of 1,2-diols is an important transformation for organic synthesis. Various methods have been developed to achieve direct monoalkylation of one of two hydroxyl groups in 1,2-diols. Usually an excess amount of 1,2-diols is used. ${ }^{1}$ Therefore, many stoichiometric methods have been developed, such as reductive cleavage of acetals, ${ }^{2}$ use of polymer resins, ${ }^{3}$ thallium salts, ${ }^{4}$ monosodium salts, ${ }^{5}$ silver oxide, ${ }^{6}$ dibutyltin oxide, ${ }^{7}$ arylboronic acid ${ }^{8}$ and direct allylation of 1,2-diols through intramolecular dehydrohalogenation. ${ }^{9}$ However, only a few catalytic processes have been demonstrated for limited examples utilizing tin dichloride, ${ }^{10}$ phase transfer catalysts, ${ }^{11}$ and crown ether. ${ }^{12}$ Thus, development of a general, highly selective, and convenient catalytic protocol for monoalkylation of 1,2-diols remains to be exploited.

We have developed the methods for catalytic monoacylation of 1,2-diols in which 1,2-diols are selectively activated with Lewis acid such as dimethyltin dichloride ${ }^{13}$ or copper(II) salts ${ }^{14}$ in the presence of a weak base. We envisioned that this process could be extended to catalytic monoalkylation of 1,2-diols. We present here a general catalytic monoalkylation method for 1,2-diols catalyzed by copper(II) salt or boronic acids under mild condition.

Key words: Diol; Alkylation; Lewis acid; Allylation, Benzylation

*Corresponding author, Tel +81-95-819-2429, Fax +81-95-819-2476, E-mail onomura@nagasaki-u.ac.jp (O. Onomura) 


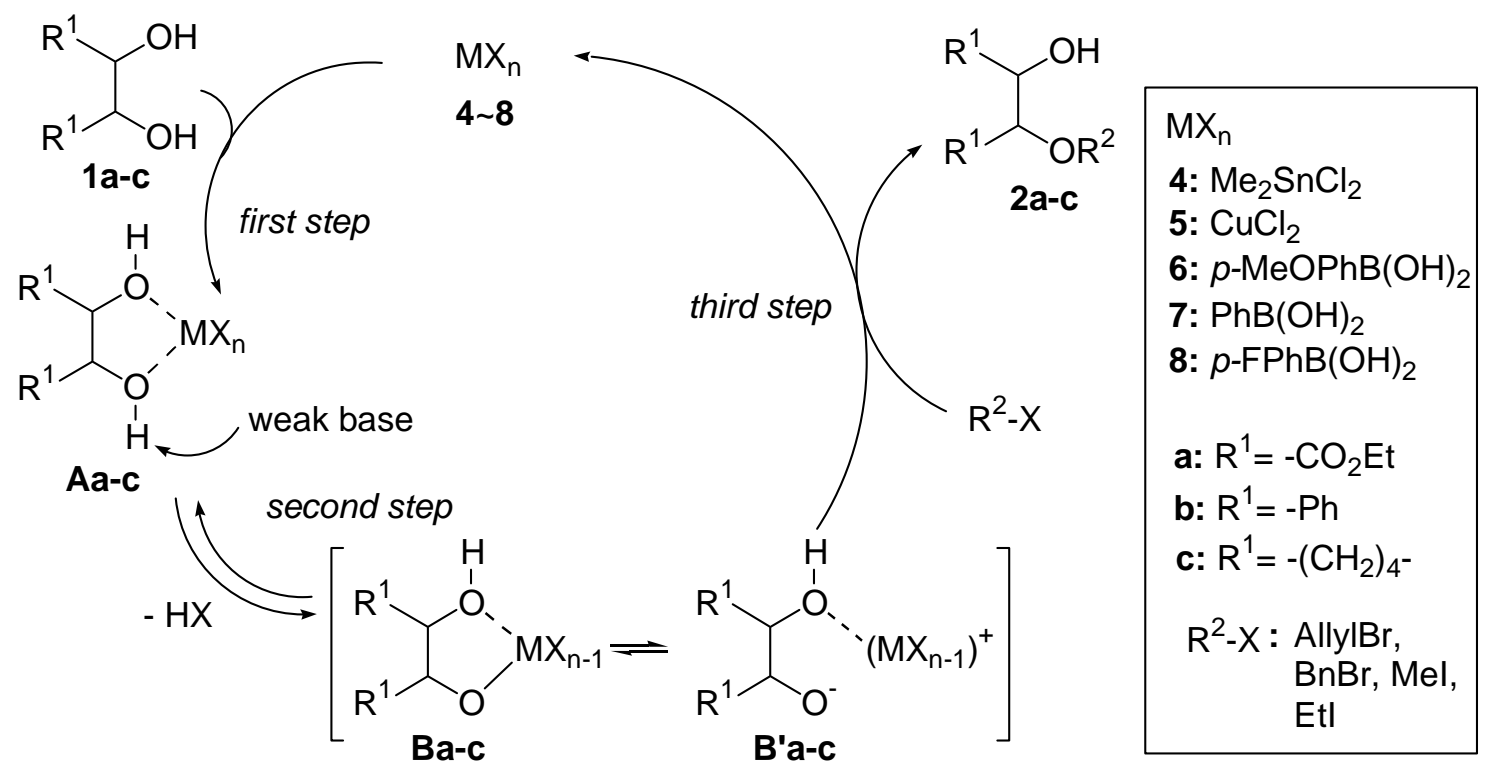

Scheme 1. Working hypothesis for 1,2-diols selective monoalkylation catalyzed by Lewis acid.

Our working hypothesis for selective monoalkylation of 1,2-diols is depicted in Scheme 1. Here $\mathrm{MX}_{\mathrm{n}}$ 4-8 and $\mathrm{R}^{2}-\mathrm{X}$ represent Lewis acids and alkylating reagents, respectively. The monoalkylation process is roughly divided into three steps: 1) 1,2-diol 1a-c is recognized by $\mathrm{M}^{\mathrm{n}+}$ because of its bidentate character of forming complex Aa-c; 2) complex Aa-c is selectively deprotonated by weak base, such as metal carbonate affording alkoxide Ba-c because of its lowered pKa value than 1a-c through association with 4-8; 3) since Ba-c (or B'a-c) has a higher reactivity than 1a-c, it is selectively monoalkylated by $\mathrm{R}^{2}-\mathrm{X}$. The resulting monoalkylated product $\mathbf{2 a - c}$ can not coordinate with 4-8, therefore second alkylation of 2a-c does not proceed.

Based on this concept, we employed allyl bromide as $\mathrm{R}^{2}-\mathrm{X}$ and diethyl L-tartrate (1a) as a diol for initial test of various Lewis acids as catalysts (Eq. 1). The results are summarized in Table 1.

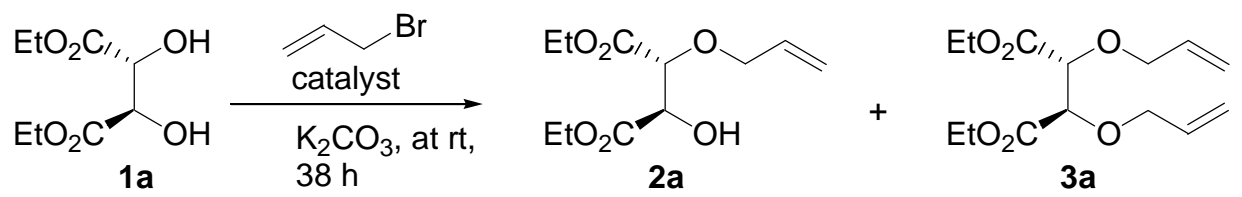


Table 1. Catalytic monoallylation of 1a. ${ }^{\mathrm{a}}$

\begin{tabular}{lllll}
\hline run & catalyst & solvent & \multicolumn{2}{c}{ Yield (\%) $^{\mathrm{b}}$} \\
& & & $\mathbf{2 a}$ & 3a \\
\hline 1 & $\mathrm{Me}_{2} \mathrm{SnCl}_{2}(\mathbf{4})$ & $\mathrm{THF}$ & 12 & $\mathrm{nd}^{\mathrm{c}}$ \\
2 & $\mathbf{4}$ & $\mathrm{CH}_{2} \mathrm{Cl}_{2}$ & 21 & trace \\
3 & $\mathbf{4}$ & $\mathrm{DMF}$ & 50 & 2 \\
4 & $\mathrm{CuCl}_{2}(\mathbf{5})$ & $\mathrm{DMF}$ & 86 & trace \\
5 & $p-\mathrm{MeOPhB}(\mathrm{OH})_{2}(\mathbf{6})$ & $\mathrm{DMF}$ & 23 & trace \\
6 & $\mathrm{PhB}(\mathrm{OH})_{2}(\mathbf{7})$ & $\mathrm{DMF}$ & 21 & 2 \\
7 & $p-\mathrm{FPhB}(\mathrm{OH})_{2}(\mathbf{8})$ & $\mathrm{DMF}$ & 27 & 3 \\
\hline${ }^{a}$ To a mixture of 1a, $\mathrm{K}_{2} \mathrm{CO}_{3}(1.5$ equiv), and catalyst (0.1 equiv) in solvent was added allyl \\
bromide (2 equiv). The mixture was stirred for 38 3 h at rt. ${ }^{\circ}$ Isolated yield. ${ }^{\mathrm{C}}$ Not detected.
\end{tabular}

First, we examined dimethyltin dichloride (4) as a catalyst, which has been used to effectively catalyze monobenzoylation of diols, ${ }^{13 a}$ for monoallylation of 1a with allyl bromide. Use of THF or $\mathrm{CH}_{2} \mathrm{Cl}_{2}$ led to monoallylated product 2a obtained in only $12 \%$ or 21\% yield (runs 1 and 2), while the yield of 2a was improved in DMF (run 3). Change of catalyst to $\mathrm{CuCl}_{2}$ (5) instead of $\mathbf{4}$, led to an improved yield for $2 \mathrm{a}$ (86\% yield) (run 4). Phenylboronic acids 6-8 were not effective for this reaction (runs 5-7). In all cases, the formation of diallylated product $3 \mathbf{a}$ was negligible.

Encouraged by this impressive results, we examined the system for $d$-hydrobenzoin (1b) and cis-cyclohexane-1,2-diol (1c) (Eq. 2). The results are summarized in Table 2.

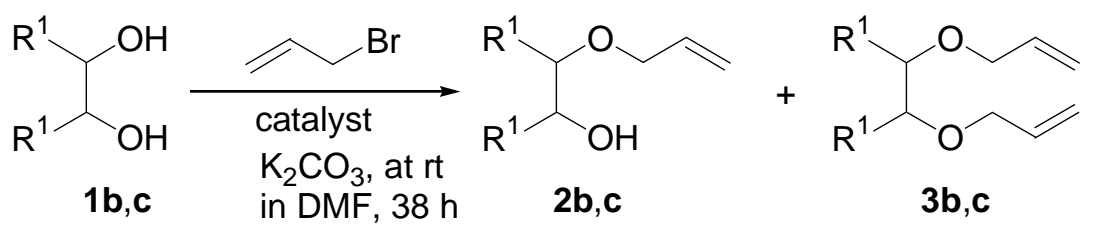

In this case, however, $\mathbf{5}$ did not effectively catalyze monoallylation of $\mathbf{1 b}$ and $\mathbf{1 c}$, affording a disappointing yield of $15 \%$ and $4 \%$ for $\mathbf{2 b}$ and $\mathbf{2 c}$, respectively (runs 2 and 7). Replacement of $\mathbf{5}$ with catalyst $\mathbf{4}$ slightly improved the yields of $\mathbf{2 b}$ and $\mathbf{2 c}$ (runs 1 and 6), while boronic acids 6-8 efficiently catalyzed monoallylation of $\mathbf{1 b}$ and $\mathbf{1 c}$ (runs 3-5, 8-10). More interestingly, substituents at para-position on phenylboronic acids showed opposite effect on the catalytic ability with respect to $\mathbf{1 b}$ and $\mathbf{1 c}$. That is, for monoallylation of $\mathbf{1 b}, \mathbf{6}$ substituted with electron donating methoxyl group improved the yield of $\mathbf{2 b}$, while $\mathbf{8}$ substituted with electron deficient fluoro group gave lower yield (runs 3-5). On the contrary, for that of 1c, use of $\mathbf{8}$ afforded 2c in better yield than that of 6 (runs 7-9). 
Table 2. Catalytic monoallylation of $\mathbf{1 b}, \mathbf{c}^{\mathrm{a}}{ }^{\mathrm{a}}$

\begin{tabular}{|c|c|c|c|c|}
\hline \multirow{2}{*}{ run } & \multirow{2}{*}{ 1,2-diol } & \multirow{2}{*}{ catalyst } & \multicolumn{2}{|c|}{ Yield (\%) } \\
\hline & & & 2 & 3 \\
\hline 1 & \multirow[b]{2}{*}{$\mathrm{Ph}_{1,,} \mathrm{O}$} & 4 & $35^{\mathrm{b}}$ & $\mathrm{nd}^{\mathrm{c}}$ \\
\hline 2 & & 5 & $15^{\mathrm{b}}$ & $\mathrm{nd}^{\mathrm{c}}$ \\
\hline 3 & \multirow[b]{3}{*}{ 1b } & 6 & $75^{\mathrm{b}}$ & $\mathrm{nd}^{\mathrm{c}}$ \\
\hline 4 & & 7 & $70^{\mathrm{b}}$ & $\mathrm{nd}^{\mathrm{c}}$ \\
\hline 5 & & 8 & $64^{\mathrm{b}}$ & $\mathrm{nd}^{\mathrm{c}}$ \\
\hline 6 & \multirow{5}{*}{ 1c } & 4 & $12^{\mathrm{d}}$ & $\mathrm{nd}^{\mathrm{c}}$ \\
\hline 7 & & 5 & $4^{\mathrm{d}}$ & $\mathrm{nd}^{\mathrm{c}}$ \\
\hline 8 & & 6 & $61^{\mathrm{d}}$ & $\mathrm{nd}^{\mathrm{c}}$ \\
\hline 9 & & 7 & $68^{\mathrm{d}}$ & $\mathrm{nd}^{\mathrm{c}}$ \\
\hline 10 & & 8 & $78^{d}$ & $\mathrm{nd}^{\mathrm{c}}$ \\
\hline
\end{tabular}

${ }^{a}$ To a mixture of diol, $\mathrm{K}_{2} \mathrm{CO}_{3}$ (1.5 equiv), and catalyst (0.1 equiv) in DMF was added allyl bromide (2 equiv). The mixture was stirred for $38 \mathrm{~h}$ at rt. ${ }^{\mathrm{b}}$ Isolated yield. ${ }^{\mathrm{c}}$ Not detected. ${ }^{\mathrm{d}}$ Determined by GLC.

This result indicates that there is a suitable combination between diols and catalysts to achieve an efficient catalytic cycle. The best combination seems to be controlled by both acidity of diols and Lewis acids. In the case of using relatively weak Lewis acid such as $\mathbf{5}$, the first and second steps could be slow, while possibly higher reactivity of resulting intermediate Ba-c would accelerate the third step (Scheme 1). On the other hand, relatively strong Lewis acid such as $\mathbf{6 - 8}$ would be favor for the first and second steps, while stabilized intermediate Ba-c may make the third step sluggish. Thus, suitable catalyst, which maximizes the overall reaction rate, would be determined depending on each diol's acidity. Diol 1a has acidic hydroxyl groups that easily form a complex Ba with relatively weak Lewis acid 5, which enhances the reaction rate for allylation. On the other hand, less acidic diol $\mathbf{1 c}$ would be slow to form a complex $\mathbf{B c}$, thus needs strong Lewis acid $\mathbf{8}$ to achieve fast formation of $\mathbf{B c}$. Since the acidity of $\mathbf{1 b}$ is considered to be located between 1a and 1c, the result that the best catalyst for allylation of $\mathbf{1 b}$ is electron-rich boronic acid $\mathbf{6}$ seems to meet this.

Next, we examined the catalytic process for diols 1a-d with various alkylating reagents (Eq. 3). Table 3 shows the results.

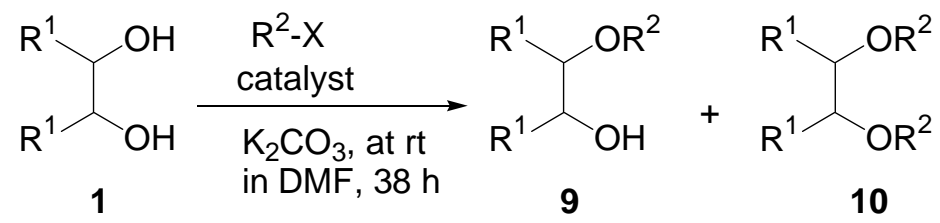


Table 3. Catalytic monoalkylation of 1,2-diols ${ }^{\mathrm{a}}$

\begin{tabular}{|c|c|c|c|c|c|c|c|c|}
\hline \multirow{2}{*}{ run } & \multirow{2}{*}{ diol } & \multirow{2}{*}{ catalyst } & \multirow{2}{*}{\multicolumn{2}{|c|}{$\mathrm{R}^{2}-\mathrm{X}$ (equiv) }} & \multicolumn{4}{|c|}{ product (yield: \%) } \\
\hline & & & & & \multicolumn{2}{|l|}{9} & \multicolumn{2}{|l|}{10} \\
\hline 1 & 1a & 5 & MeI & (10) & 9a(Me) & $65^{\mathrm{b}}$ & 10a(Me) & $<1$ \\
\hline 2 & 1a & 5 & $\mathrm{BnBr}$ & (1.2) & 9a(Bn) & $79^{\mathrm{b}}$ & 10a(Bn) & $<1$ \\
\hline 3 & $1 \mathbf{a}$ & 5 & EtI & (5) & $9 a(E t)$ & $45^{\mathrm{b}}$ & $10 a(E t)$ & $<1$ \\
\hline 4 & $1 b$ & 6 & MeI & (10) & $9 b(\mathrm{Me})$ & $89^{b}$ & 10b(Me) & $\mathrm{nd}^{\mathrm{c}}$ \\
\hline 5 & $1 b$ & 6 & $\mathrm{BnBr}$ & (1.5) & $9 b(B n)$ & $64^{\mathrm{b}}$ & 10b(Bn) & $n d^{c}$ \\
\hline 6 & 1c & 8 & $\mathrm{BnBr}$ & (1.5) & $9 c(B n)$ & $84^{\mathrm{b}}$ & 10c(Bn) & $\mathrm{nd}^{\mathrm{c}}$ \\
\hline $7^{\mathrm{d}}$ & 1c & 8 & $\mathrm{BnBr}$ & (1.5) & $9 c(B n)$ & $99^{\mathrm{b}}$ & 10c(Bn) & $\mathrm{nd}^{\mathrm{c}}$ \\
\hline $8^{e}$ & 1c & 8 & EtI & (5) & $9 c(E t)$ & $79^{\mathrm{f}}$ & $10 c(E t)$ & $\mathrm{nd}^{\mathrm{c}}$ \\
\hline 9 & & 8 & $\mathrm{BnBr}$ & (1.5) & 9d(Bn) & $25^{\mathrm{b}}$ & 10d(Bn) & $\mathrm{nd}^{\mathrm{c}}$ \\
\hline $10^{\mathrm{g}}$ & & 8 & $\mathrm{BnBr}$ & (3) & 9d(Bn) & $91^{\mathrm{b}}$ & 10d(Bn) & 1 \\
\hline & 1d & & & & & & & \\
\hline
\end{tabular}

${ }^{\mathrm{a}}$ To a mixture of diol, $\mathrm{K}_{2} \mathrm{CO}_{3}$ (1.5 equiv), and catalyst (0.1 equiv) in DMF was added $\mathrm{R}^{2}$-X. The mixture was stirred for $38 \mathrm{~h}$ at rt. ${ }^{\mathrm{b}}$ Isolated yield. ${ }^{\mathrm{c}}$ Not detected. ${ }^{\mathrm{d}} \mathrm{MeCN}$ containing 0.2 equiv of $\mathrm{Et}_{4} \mathrm{NBr}$ was used instead of DMF. ${ }^{\mathrm{e}} 46 \mathrm{~h}$ of reaction time was applied. ${ }^{\mathrm{f}}$ Determined by GLC. ${ }^{\mathrm{g}} \mathrm{A}$ mixture of toluene and $50 \% \mathrm{KOH}$ containing 1 equiv of $\mathrm{Et}_{4} \mathrm{NBr}$ was used instead of $\mathrm{DMF}-\mathrm{K}_{2} \mathrm{CO}_{3}$.

These alkylating reagents selectively afforded monoalkylated products $\mathbf{9 a - d}$ in good to moderate yields. Use of excess amount of alkylating reagent was required because of its low reactivity. Even in cases where large excess amount of alkylating reagents were used, formation of corresponding dialkylated products 10a-d were minute (runs 1,3,4,8). It was found that $\mathrm{MeCN}$ and $\mathrm{Et}_{4} \mathrm{NBr}$ as a phase transfer catalyst improved the yield of 9c(Bn) (run 5). Although trans-cyclohexane-1,2-diol 1d afforded only poor yield (25\%) of $\mathbf{9 e}(\mathbf{B n})$ under standard condition (run 9), the yield was significantly improved when a mixture of toluene and $50 \% \mathrm{KOH}$ containing 1 equiv of $\mathrm{Et}_{4} \mathrm{NBr}$ was used (run 10).

Moreover, the method was found to be applicable to monobenzylation of 1,3-diol 1d (Eq. 4).

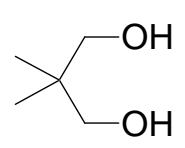

$1 e$

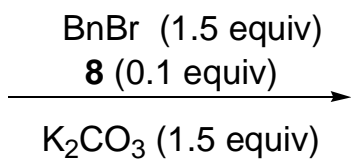

in DMF, at rt, $38 \mathrm{~h}$

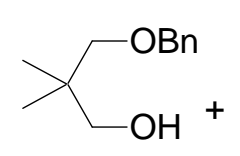

9e(Bn) $88 \%$ yield

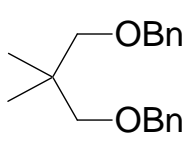

$10 \mathrm{e}(\mathrm{Bn})$

not detected
(4)

To demonstrate chemoselectivity 1c and cyclohexanol (11) were subjected to this 
method and only 1a was monbenzylated to afford $\mathbf{9 c ( B n )}$ in 96\% yield (Eq. 5).

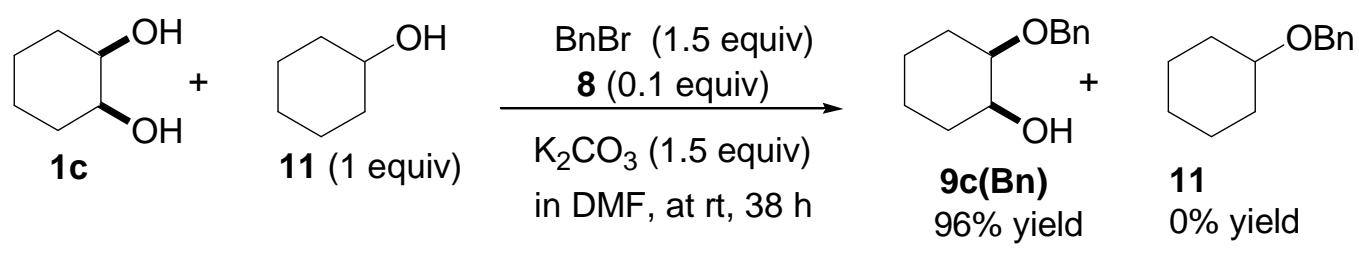

In conclusion, we have developed a new catalytic monoalkylation method for 1,2-diols. This method is convenient and can be widely applied, since it does not require a strong base such as $\mathrm{NaH}$ therefore tolerant to ester groups. Moreover, we have found that the choice of catalysts for monoalkylation of 1,2-diols depended on their acidity. The asymmetric version of monoalkylation is currently underway.

\section{Acknowledgements}

This work was supported by The Naito Foundation.

\section{References and notes}

1. (a) Lee, G. H.; Choi, E. B.; Lee, E.; Pak, C. S. J. Org. Chem. 1994, 59, 1428-1443;

(b) Guidry, E. N.; Cantrill, S. J.; Stoddart, J. F.; Grubbs, R. H. Org. Lett. 2005, 7, 2129-2132.

2. (a) Takano, S.; Akiyama, M.; Sato, S.; Ogasawara, K. Chem. Lett. 1983, 1593-1596;

(b) Mikami, T.; Asano, H.; Mitsunobu, O. Chem. Lett. 1987, 2033-2036; (c) Takasu, M.; Naruse, Y.; Yamamoto, H. Tetrahedron Lett. 1988, 29, 1947-1950; (d) Barton, D. H. R.; Zhu, J. Tetrahedron 1992, 48, 8337-8346.

3. (a) Leznoff, C. C. Acc. Chem. Res. 1978, 11, 327-333; (b) Nishiguchi, T.; Kawamine, K.; Ohtsuka, T. J. Chem. Soc., Perkin Trans. 1 1992, 153-156.

4. Kalinowski, H.-O.; Crass, G.; Seebach, D. Chem. Ber. 1981, 114, 477-487.

5. McDougal, P. G.; Rico, J. G.; Oh, Y.-I.; Condon, B. D. J. Org. Chem. 1986, 51, 3388-3390.

6. Bouzide, A.; Sauve, G. Tetrahedron Lett. 1997, 38, 5945.

7. (a) Nagashima, N.; Ohno, M. Chem. Pharm. Bull. 1991, 39, 1972-1982; (b) Scheufler, F.; Maier, M. E. Synlett 2001, 1221-1224; (c) Schmidt, B.; Nave, S. Adv. Synth, Catal. 2007, 349, 215-230.

8. Oshima, K.; Kitazono, E.; Aoyama, Y. Tetrahedron Lett. 1997, 38, 5001-5004.

9. Jha, S. C.; Joshi, N. N. J. Org. Chem. 2002, 67, 3897-3899.

10. Petursson, S.; Webber, J. M. Carbohydr. Res. 1982, 103, 41-52.

11. De La Zerda, J.; Barak, G.; Sasson, Y. Tetrahedron 1989, 45, 1533-1536.

12. Bessodes, M.; Boukarim, C. Synlett 1996, 1119-1120. 
13. (a) Maki, T.; Iwasaki, F.; Matsumura, Y. Tetrahedron Lett. 1998, 39, 5601-5604; (b) Iwasaki, F.; Maki, T.; Nakashima, W.; Onomura, O.; Matsumura, Y. Org. Lett. 1999, 1, 969-972; (c) Iwasaki, F.; Maki, T.; Onomura, O.; Nakashima, W.; Matsumura, Y. J. Org. Chem. 2000, 65, 996-1002; (d) Demizu, Y.; Kubo, Y.; Miyoshi, H.; Maki, T.; Matsumura, Y.; Moriyama, N.; Onomura, O. Org. Lett. 2008, 10, 5075-5077.

14. (a) Matsumura, Y.; Maki, T.; Murakami, S.; Onomura, O. J. Am. Chem. Soc. 2003, 125, 2052-2053; (b) Matsumura, Y.; Maki, T.; Tsurumaki, K.; Onomura, O.; Tetrahedron Lett. 2004, 45, 9131-9134; (c) Matsumoto, K.; Mitsuda, m.; Ushijima, N.; Demizu, Y.; Onomura, O.; Matsumura, Y. Tetrahedron Lett. 2006, 47, 8453-8456; (d) Demizu, Y.; Matsumoto, K.; Onomura, O.; Matsumura, Y. Tetrahedron Lett. 2007, 48, 7605-7609.

15. Typical procedure for monoallylation of 1,2-diol; To a solution of 1a,b (1 mmol) and catalyst $(0.1 \mathrm{mmol})$ in DMF $(2 \mathrm{~mL})$ was added $\mathrm{K}_{2} \mathrm{CO}_{3}(1.5 \mathrm{mmol})$ and allyl bromide ( $2 \mathrm{mmol}$ ) at room temperature. After stirring for $38 \mathrm{~h}$, the mixture was poured into water and extracted three portion of ethyl acetate. The organic layer was combined and dried over $\mathrm{MgSO}_{4}$. After filtration, the organic portion was concentrated under reduced pressure. The resulting residue was purified by silica gel column chromatography. 